
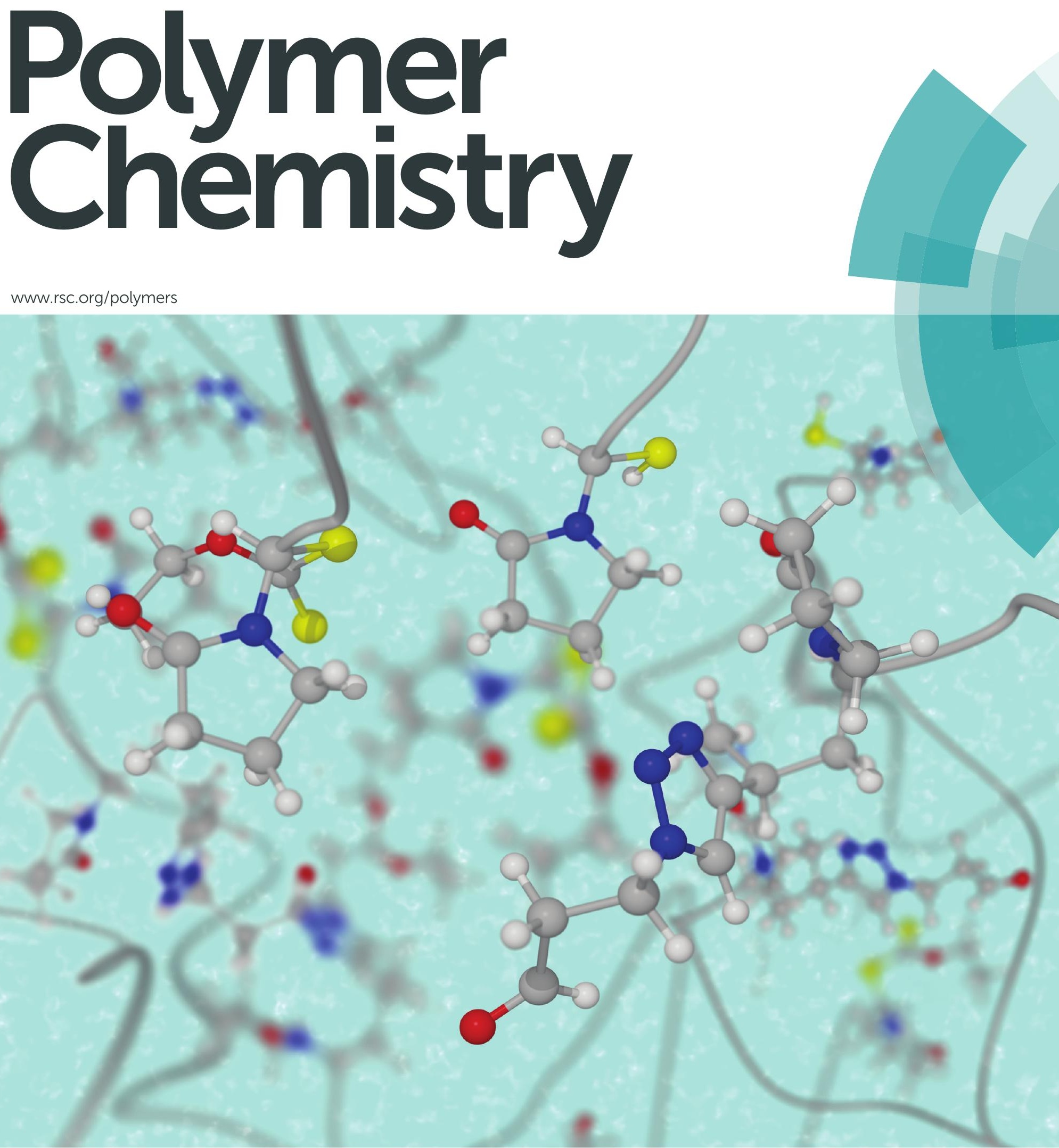

ISSN 1759-9954

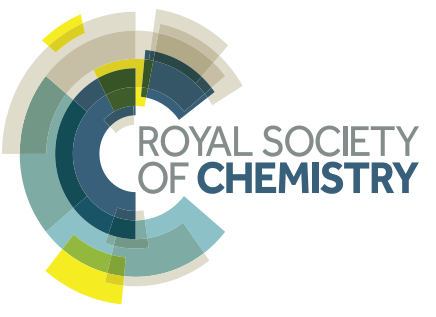

\section{PAPER}

Bert Klumperman et al.

Synthesis of $\alpha, \omega$-heterotelechelic PVP for bioconjugation, via a one-pot orthogonal end-group modification procedure

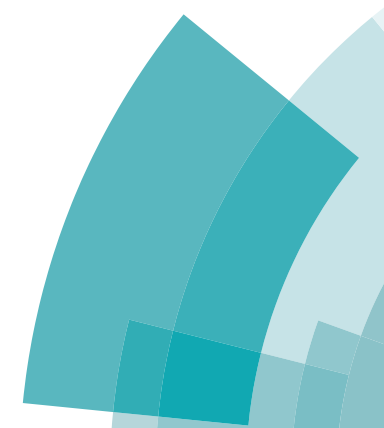




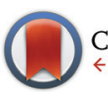

CrossMark $\leftarrow$ click for updates

Cite this: Polym. Chem., 2016, 7, 6450

Received 25th July 2016

Accepted 27th August 2016

DOI: 10.1039/c6py01296e

www.rsc.org/polymers

\title{
Synthesis of $\alpha, \omega$-heterotelechelic PVP for bioconjugation, via a one-pot orthogonal end-group modification procedure $\uparrow$
}

\author{
Paul. W. Reader, Rueben Pfukwa, Simbarashe Jokonya, Gareth E. Arnott and \\ Bert Klumperman*
}

\begin{abstract}
A simple one pot orthogonal procedure for synthesizing $\alpha$-aldehyde, $\omega$-thiol heterotelechelic poly( $N$-vinylpyrrolidone) (PVP) is introduced. Firstly we designed a xanthate chain transfer agent with an acetal protected aldehyde functionality in the leaving group, then we synthesized $\alpha$-acetal $\omega$-xanthate end-functional PVP, via a RAFT-mediated polymerization. The end-groups were modified via a facile, modular protocol, by first aminolysing the $\omega$-xanthate end-groups to form thiols, using an excess of a primary amine, and subsequently acidifying the reaction medium to simultaneously convert excess primary amine to its (non-interfering) quaternary ammonium salt form, as well as effect the acid-catalysed deprotection of the acetal into an aldehyde functionality, to access the $\alpha$-aldehyde, $\omega$-thiol-PVP. Finally, we demonstrated the utility of these end-groups by performing conjugations with model small molecules. This study establishes a facile procedure for accessing different and bio-relevant end-functional groups with a biocompatible vinyl polymer, suitable for making drug delivery vehicles.
\end{abstract}

\section{Introduction}

Bioconjugates of synthetic vinyl polymers have many biomedical applications, including as drug delivery vehicles. ${ }^{1-4}$ Often the conjugates are prepared by coupling the reactive end-groups of telechelic polymers with complementary functional groups in bioactive compounds or bio(macro)molecules. ${ }^{1,2}$ In this regard, heterotelechelic polymers are particularly interesting because the different end-groups can often be addressed orthogonally. ${ }^{5-7}$ Synthetic strategies for preparing telechelic polymers have been enhanced through advances made in reversible deactivation radical polymerization (RDRP), which enable routine access to precise polymers, with defined end-groups usable in bioconjugate formation. ${ }^{3,8-13}$ One of the main RDRP processes is the reversible addition fragmentation chain transfer (RAFT) technique, mediated by thiocarbonyl thio compounds, commonly referred to as RAFT agents. ${ }^{14}$ RAFT agents generally consist of a leaving (R) group, and a thiocarbonyl thio functional (Z) group, both retained in the final polymer as $\alpha$ and $\omega$ end-groups, respectively. Functional groups incorporated into the $\mathrm{R}$ or $\mathrm{Z}$ groups, are retained as $\alpha$ and $\omega$ end-functionalities, respectively.

Department of Chemistry and Polymer Science, Stellenbosch University, Private Bag X1, Matieland 7602, South Africa. E-mail: bklump@sun.ac.za

$\dagger$ Electronic supplementary information (ESI) available. See DOI: 10.1039/ c6py01296e
$\mathrm{Z}$ groups are however unstable to nucleophiles, are often coloured and degrade into odorous compounds. Therefore, the in situ synthesis of end-functional polymers is traditionally conducted with R-group functional RAFT agents, for example, bearing activated esters, ${ }^{15,16}$ activated disulfides, ${ }^{17}$ biotin, ${ }^{6}$ or azide functionalities, ${ }^{18}$ yielding $\alpha$-end telechelic functional polymers, for use in bioconjugate formation. The $\omega$-end thiocarbonyl thio moieties are readily converted into thiols by treating the polymer with nucleophiles, mainly primary amines. ${ }^{17,19}$ Thiol end-groups have numerous functionalization possibilities, including click-type Michael addition reactions with acrylate and maleimide functionalities and disulfide formation, e.g. with cysteine residues of peptides or proteins. ${ }^{20,21}$

Whilst the synthesis of mono-telechelic functional polymers is a mature paradigm, there are still only a few reports on the synthesis of $\alpha, \omega$-heterotelechelic polymers. One of these approaches entails using RAFT agents with functionalised $\mathrm{R}$ and $\mathrm{Z}$ groups to directly synthesise $\alpha, \omega$-heterotelechelic functional polymers. ${ }^{22}$ The nucleophilic and thermal instability of thiocarbonyl thio moieties, however, makes the $\omega$-endfunctionality inherently unstable, encumbering this approach. Other methods utilise a combination of functionalised R-groups, for $\alpha$-end-functionality; and either aminolysis of the $\mathrm{Z}$ group to form a thiol, ${ }^{5,23}$ or the use of radical-radical coupling, with concomitant $\mathrm{Z}$ group removal, ${ }^{6,7}$ to install $\omega$-functionality. Heterotelechelic $\alpha$-amine, $\omega$-thiol poly $(N$-vinylpyrrolidone) (PVP), has been obtained by simply treating PVP, 
synthesized using $O$-ethyl $S$-(phthalimidomethyl) xanthate RAFT agent, with hydrazine, to effect both the hydrazinolysis of the phthalamidomethyl $\mathrm{R}$ group, to an amine, and the aminolysis of the $\omega$-xanthate chain end to a thiol at the same time. ${ }^{24}$ There is a lot of scope, however, to introduce other combinations of bio-relevant end-functionalities using facile, preferably one pot, and orthogonal procedures, in order to further enhance this technology. Orthogonally addressable $\alpha, \omega$-heterotelechelic functionalities such as aldehydes and thiols interest us, because they have many applications in bioconjugate formation. ${ }^{4,21,25}$ Aldehydes and thiols, react readily with amine and thiol functionalities, respectively, which are found in lysine and cysteine residues, respectively, of peptides and proteins, under relatively undemanding conditions. PVP, which can be synthesized via the RAFT-mediated polymerization of $\mathrm{N}$-vinylpyrrolidone (NVP), ${ }^{26}$ with xanthate RAFT agents, is an established biocompatible polymer, ${ }^{27,28}$ and an attractive choice in the design of $\alpha, \omega$-heterotelechelic polymers for bioconjugate formation. ${ }^{25,29}$

Herein we introduce a facile, one-pot and orthogonal method converting RAFT-made $\alpha$-acetal, $\omega$-xanthate PVP, into $\alpha$-aldehyde, $\omega$-thiol heterotelechelic PVP. Firstly, we polymerized NVP, via RAFT-mediated polymerization using a triazole based xanthate RAFT agent incorporating an acetalprotected aldehyde in the R group. Along the way we optimised the structure of the triazole based $\mathrm{R}$ group, to obtain good control over the RAFT polymerization of NVP; as well as the structure of the triazole linked acetal, in order to enhance its acid catalysed deprotection into an aldehyde. Then we developed a facile, one-pot two-step protocol for aminolysing the $\mathrm{Z}$ group, and then deprotecting the acetal into aldehyde

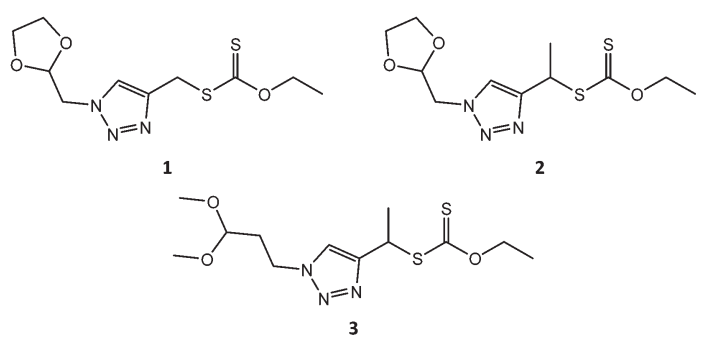

Fig. 1 RAFT agent structures. functionality via acid catalysis. Finally we illustrated the use of these functional end-groups in bioconjugate formation, and stimuli $(\mathrm{pH})$ responsive release, through the use of model reactions with small organic molecules.

\section{Results and discussion}

In previous work, in our group, we used RAFT agents with a (1-phenyl-1H-1,2,3-triazol-4-yl)methyl (triazole based) leaving group to, successfully, control the polymerizations of vinyl acetate, NVP, $n$-butyl acrylate and styrene. ${ }^{30}$ We used this approach to introduce a functional group, i.e. an acetal protected aldehyde, into the R group of RAFT agent 1 (Fig. 1), synthesised via the copper-catalyzed azide alkyne coupling reaction (Scheme S1 $\dagger$ ). ${ }^{18,30}$ NVP was subsequently polymerized using RAFT agent 1, targeting two degrees of polymerisation (DP), 100 and 200, respectively (entries 1 and 2, Table 1). The obtained polymers, however, exhibited high $D$ values, of 1.91 and 1.73 , respectively, much higher than expected for a well-behaved RDRP process. We attributed this to a poor leaving group ability of RAFT agent 1's R group, compared to the PVP macroradical, causing hybrid behaviour. ${ }^{30}$ In our earlier successful RAFT polymerizations, with triazole-based RAFT agents, the triazole was directly linked (conjugated) to a phenyl ring, on the $\mathrm{N}-1$ of the triazole, ${ }^{30}$ which probably complemented the triazole's pseudo-aromatic resonance, thereby improving its leaving group ability. RAFT agent 1, however, contains a methylene group as a substituent on the N-1 of the triazole, which cannot offer the same resonance stabilisation as the phenyl moiety in our earlier work. We therefore introduced a methyl substituent into the $\mathrm{R}$ group (i.e. RAFT agent 2 , Scheme S2 $\dagger$ ), so as to form a more stable secondary radical during the polymerization reaction, with a better leaving group ability. Pleasingly, the polymerisation of NVP using RAFT agent 2 provided much better control as evidenced by the low $D$ values (entries 3-5, Table 1), affirming our earlier hypothesis that the poor control exhibited by RAFT agent 1 was due to the poor quality of its leaving group. Subsequent ${ }^{1} \mathrm{H}$ NMR spectroscopic analysis confirmed the retention of $\alpha$-acetal (methylene ' $g$ ' at $4.47 \mathrm{ppm}$ and methine ' $h$ ' at $5.18 \mathrm{ppm}$ ) and $\omega$-xanthate (methylene ' $f$ ' at $4.60 \mathrm{ppm}$ ) end-groups in the polymers (Fig. 2). The ratio of $\alpha: \omega$-end groups, calculated using the

Table 1 RAFT-mediated polymerization of NVP

\begin{tabular}{|c|c|c|c|c|c|c|c|c|}
\hline Entry & RAFT agent & {$[\mathrm{M}]:[\mathrm{RAFT}]:[\mathrm{AIBN}]$} & $\alpha^{a}(\%)$ & Time (h) & $M_{\mathrm{n}, \text { theo }}\left(\mathrm{g} \mathrm{mol}^{-1}\right)$ & $M_{\mathrm{n}, \mathrm{SEC}}{ }^{b}\left(\mathrm{~g} \mathrm{~mol}^{-1}\right)$ & $M_{\mathrm{n}, \mathrm{NMR}}{ }^{c}\left(\mathrm{~g} \mathrm{~mol}^{-1}\right)$ & $Ð$ \\
\hline 1 & 1 & $100: 1: 0.20$ & 60 & 5 & 7000 & 6400 & $\mathrm{n} / \mathrm{a}^{d}$ & 1.91 \\
\hline 2 & 1 & $200: 1: 0.20$ & 62 & 5 & 14000 & 12700 & $\mathrm{n} / \mathrm{a}^{d}$ & 1.73 \\
\hline 3 & 2 & $200: 1: 0.20$ & 26 & 15 & 6100 & 4100 & 6000 & 1.20 \\
\hline 4 & 2 & $200: 1: 0.25$ & 24 & 15 & 5700 & 3500 & 5500 & 1.17 \\
\hline 5 & 2 & $200: 1: 0.33$ & 25 & 15 & 6000 & 3900 & 5900 & 1.19 \\
\hline 6 & 3 & $50: 1: 0.25$ & 60 & 20 & 3700 & 2700 & 3900 & 1.24 \\
\hline 7 & 3 & $100: 1: 0.25$ & 60 & 20 & 7000 & 5300 & 7300 & 1.16 \\
\hline
\end{tabular}

${ }^{a}$ Conversions, determined by ${ }^{1} \mathrm{H}$ NMR spectroscopy. ${ }^{34} b{ }_{\mathrm{n}}$, SEC determined by SEC in DMAc relative to PMMA standards. ${ }^{c} M_{\mathrm{n}}$, NMR determined by ${ }^{1} \mathrm{H}$ NMR spectroscopy. ${ }^{35}{ }^{d}$ It was not possible to determine end groups because chain ends were not retained quantitatively. 


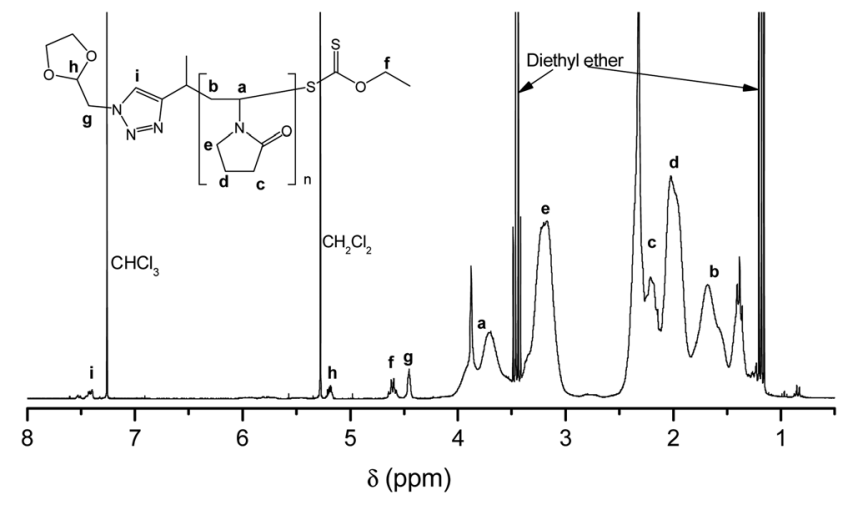

Fig. 2 Representative ${ }^{1} \mathrm{H}$ NMR spectrum of PVP, in $\mathrm{CDCl}_{3}$, synthesised using RAFT agent 2.

signals for protons ' $f$ ' : ' $g$ ', or ' $f$ ' : ' $h$ ' was above 0.9 , indicating a high degree of telechelic functionalization. Additionally, $M_{\mathrm{n}}$ values calculated from ${ }^{1} \mathrm{H}$ NMR spectroscopy $\left(M_{\mathrm{n}}\right.$, NMR $)$ were in good agreement with theoretical $M_{\mathrm{n}}$ values, (entries $3-5$, Table 1 ) indicating very good end group retention.

As part of the RAFT agent structure optimisation, we also tested the acid catalysed deprotection of the cyclic acetal $\mathrm{R}$ group functionality, into aldehyde, since acetals are known to readily convert into aldehydes with acid catalysis. ${ }^{31}$ Surprisingly, the cyclic acetal of model compound 4 remained intact upon treatment with $1 \mathrm{M} \mathrm{HCl}$ in acetone at room temperature for $24 \mathrm{~h}$ (Scheme 1), as evidenced by TLC analysis and ${ }^{1} \mathrm{H}$ NMR spectroscopic analysis of the crude reaction mixture. Repetition of the reaction under refluxing conditions resulted in structural degradation. We tried a number of deprotection conditions, e.g. using $p$-tosyl sulfonic acid or $10 \%$ iodine in acetone, without any success. ${ }^{32,33}$ It is known that acetals close to amino groups are more resistant to acid catalysed deprotection, ${ }^{36}$ therefore we reasoned that the failed deprotection of $\mathbf{4}$ was probably caused by the close proximity of the acetal to the triazole-ring. As shown in Scheme 2, it is likely that the triazole ring's N-3 atom, being the most basic, ${ }^{37}$ will be rapidly protonated in acidic media (4B). For hydrolysis to occur, one of the acetal oxygen atoms needs to be protonated to allow oxocarbenium ion formation (4D), but this would result in a doubly charged species (4C) incurring a high thermodynamic penalty. Thus the reaction probably goes no further than (4B), and forcing the conditions simply promotes acid catalysed breakdown of the starting material. The added fact that cyclic acetals are more stable than their acyclic counterparts probably enhances the difficulty in achieving hydrolysis on this compound. ${ }^{38}$ Consequently, we made two

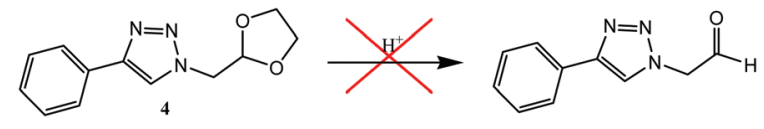

Scheme 1 Attempted acid catalysed deprotection of model acetal compound 4; $1 \mathrm{M} \mathrm{HCl}$ in acetone.

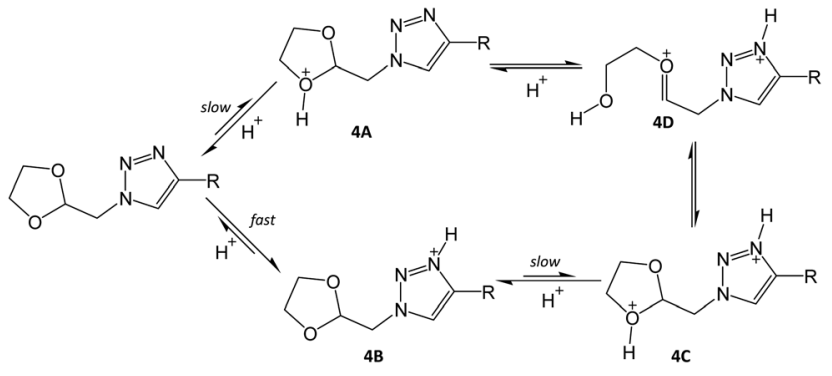

Scheme 2 Proposed mechanism of unsuccessful acetal deprotection.

changes, in order to increase the acid lability of the triazole linked acetal, firstly we increased the distance between the triazole and the acetal, by including an extra methylene group and secondly we switched to using a linear acetal.

Model compound 5 was then synthesized (Scheme S4 $\dagger$ ), and when treated with $1 \mathrm{M} \mathrm{HCl}$ in acetone, the acetal was successfully deprotected into an aldehyde in $\sim 4 \mathrm{~h}$ (Fig. S1†). Subsequently we synthesized RAFT agent 3 (Scheme S5 $\dagger$ ), bearing a linear acetal $\mathrm{R}$ group functionality, with a longer spacer between the triazole and the acetal. The RAFT-mediated polymerization of NVP, with RAFT agent 3, yielded well-defined polymers, with low $Ð$ (entries 6 and 7, Table 1). We obtained monomodal SEC traces (Fig. 3a and b), and $M_{\mathrm{n}}$ increased linearly as a function of conversion (Fig. 3c) pointing to the living character of the polymerization. Also $D$ values were consistently low, $D<1.4$ (Fig. 3c). The discrepancy between the experimental and theoretical $M_{\mathrm{n}}$ values, in Fig. 3c, was attributed to the use of PMMA standards in the SEC calibration. ${ }^{1} \mathrm{H}$ NMR spectroscopic analysis also confirmed the retention of $\alpha$-acetal (methylene ' $g$ ' at $4.37 \mathrm{ppm}$, and methine ' $h$ ' at $4.47 \mathrm{ppm}$ ) and $\omega$-xanthate (methylene ' $f$ ' at $4.60 \mathrm{ppm}$ ) end-groups in the polymers (Fig. 4). The ratio of $\alpha: \omega$-end groups, calculated using the signals for protons ' $f$ ': ' $g$ ', (or ' $f$ ': ' $h$ ') was also above 0.9 , and, $M_{\mathrm{n}}$, NMr values agreed reasonably well with theoretical $M_{\mathrm{n}}$ values, (entries 6 and 7, Table 1) indicating a very good end group retention.

\section{One-pot sequential deprotection}

Our envisioned one-pot, deprotection strategy entails aminolysis of the $\omega$-xanthate end-group into a thiol, first, and then (after lowering the $\mathrm{pH}$ of the reaction mixture) effecting the acid catalysed deprotection of the $\alpha$-acetal moiety into an aldehyde functionality. The acidic conditions utilised in acetal deprotection, also serve to quaternize excess primary amine, used for aminolysis, forming a salt that precipitates out of the reaction mixture in organic solvent, helping to prevent a deleterious side reaction, i.e. Schiff base formation between excess amine and deprotected aldehyde. We tested the proposed deprotection procedure on RAFT made PVP (entry 6, Table 1), by treating the acetone solution of the polymer with $n$-hexylamine, and then lowering the $\mathrm{pH}$ with $\mathrm{HCl}$ in dioxane, and stirring for $4 \mathrm{~h}$ (Scheme 3). Afterwards the polymer was purified by dialysis. ${ }^{1} \mathrm{H}$ NMR spectroscopy analysis of the product 

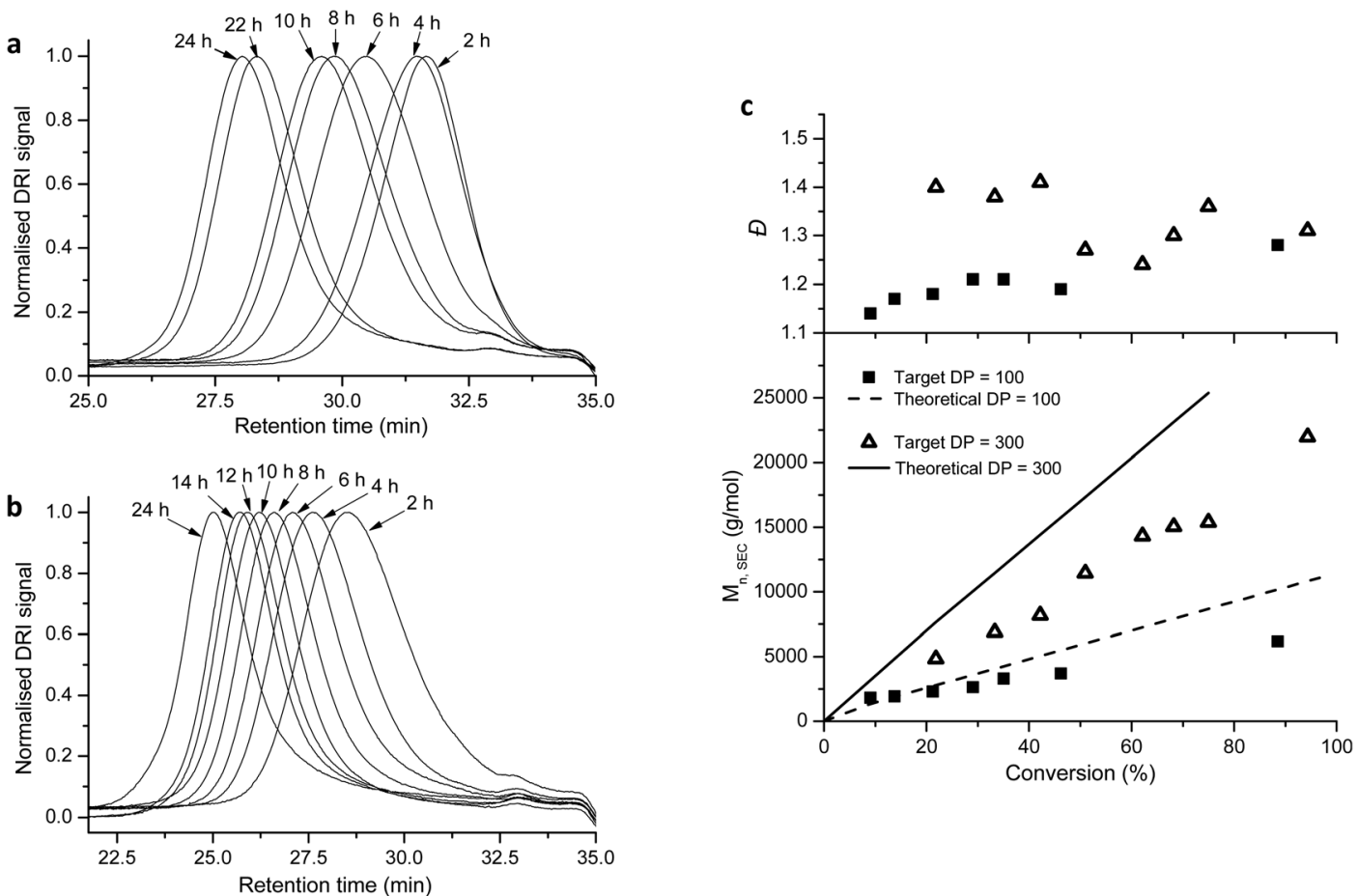

Fig. 3 SEC traces for the RAFT-mediated polymerization of NVP, with RAFT agent 3, for target DP = 100 (a), and 300 (b), and the corresponding plots of $M_{n}$ and $Đ$, as a function of conversion (c).

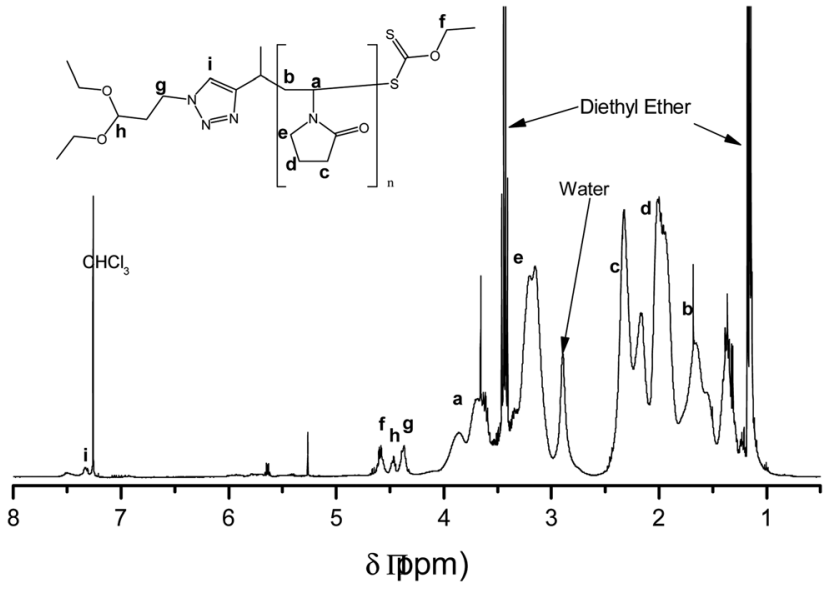

Fig. 4 Representative ${ }^{1} \mathrm{H}$ NMR spectrum of PVP, in $\mathrm{CDCl}_{3}$, synthesised using RAFT agent 3.

showed the disappearances of the $\omega$-xanthate's signal $f$, at $4.60 \mathrm{ppm}$, due to the aminolysis, and the acetal's signal $h$, at $4.48 \mathrm{ppm}$, due to the acid catalysed acetal deprotection, which was complemented by the appearance of the $\alpha$-aldehyde end-group's proton signal ( $i$ ) at 9.79 ppm (Fig. 5). The signal of the methylene protons ' $g$ ' also shifted slightly downfield from $4.4 \mathrm{ppm}$ to $4.6 \mathrm{ppm}$, presumably due to electron withdrawing effects of the aldehyde. Further analysis was conducted using SEC. Fig. 6 shows the SEC traces before and after end-group modification, recorded with RI and UV detectors. The<smiles>C=C(C(=O)N1CCCC1OC(C)C)c1cnn(CCC(OCC)OCC)c1</smiles>

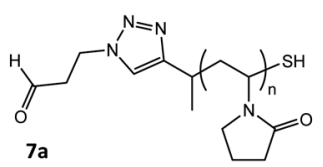

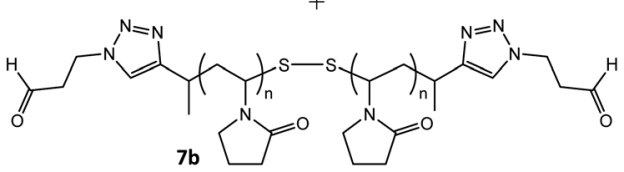

Scheme 3 One pot deprotection of RAFT made PVP (entry 6, Table 1); (a) $n$-hexylamine, acetone, r.t.; (b) $4 \mathrm{M} \mathrm{HCl}$ in dioxane, acetone, r.t.

UV detector was set at $280 \mathrm{~nm}$ to allow for selective detection of the $\omega$-xanthate chain end moiety. The elution curve, with RI detection, showed a bimodal peak for the end-group modified sample, which we attribute to disulfide formation between thiol end-groups of two polymer chains. Disulfide formation occurred because we did not take any precautions to prevent oxidising conditions, which also affirmed the successful formation of $\omega$-thiol end-groups. The UV recorded SEC trace, of the modified polymer shows no peak in the molecular 

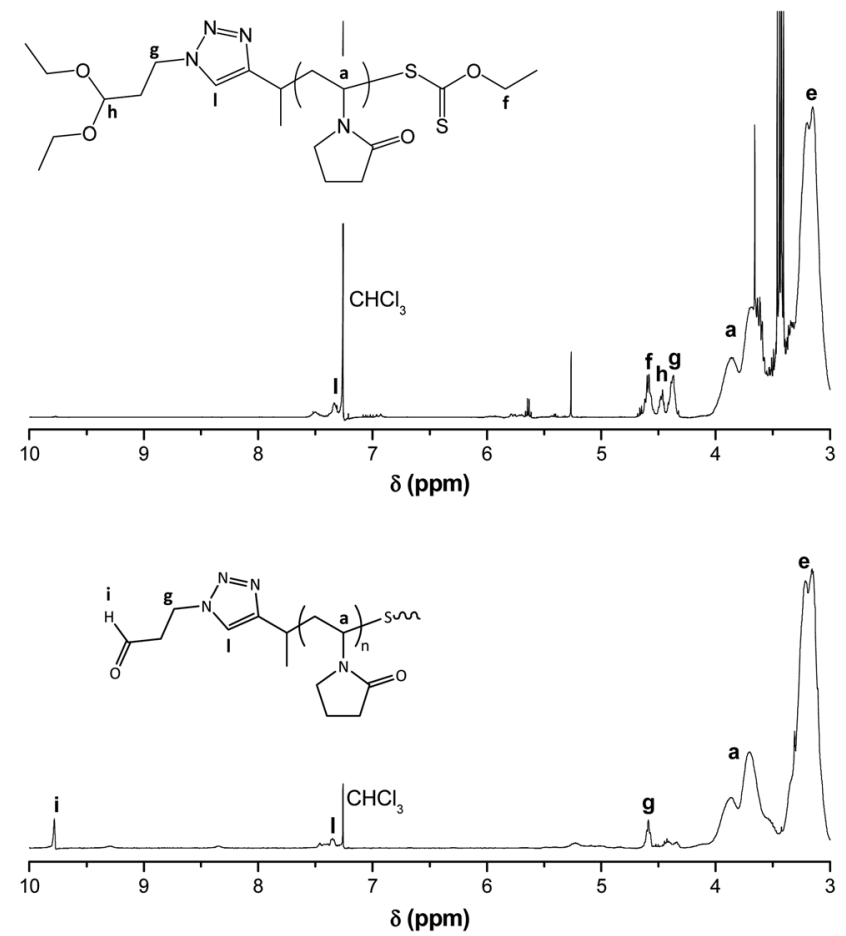

Fig. 5 Comparison of ${ }^{1} \mathrm{H}$ NMR spectra of RAFT made PVP, (entry 6 , Table 1) (top) and end-modified, aldehyde functional PVP (bottom), both in $\mathrm{CDCl}_{3}$.
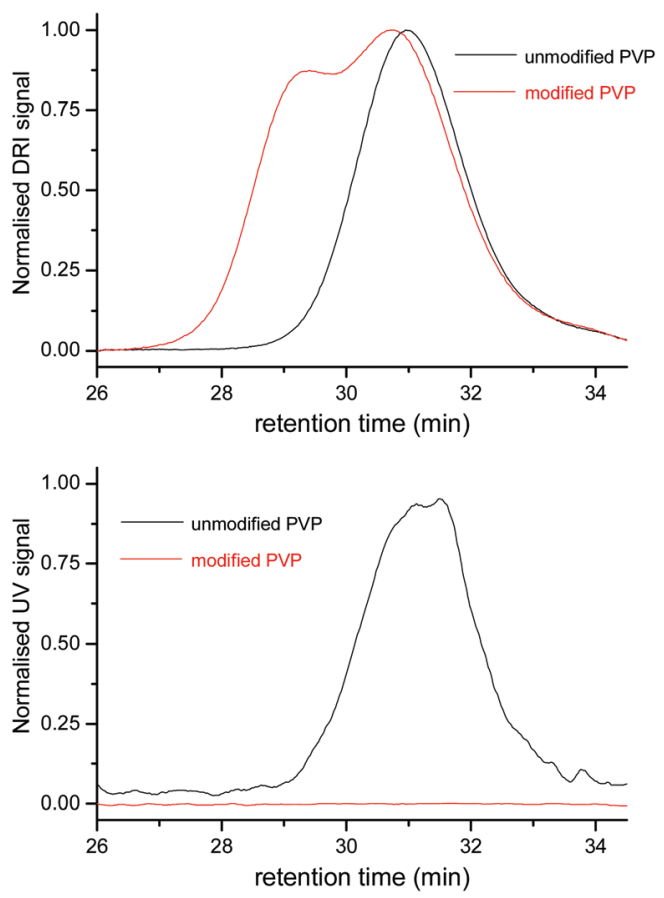

Fig. 6 SEC traces comparing the DRI (top) and UV (bottom) signals of unmodified PVP (6, Scheme 3) and end-modified PVP (7a/b, Scheme 3). weight region of the polymer, unlike with the sample before modification, confirming the removal of the xanthate endgroups. Put together, the ${ }^{1} \mathrm{H}$ NMR spectroscopy and SEC analysis evidence a successful one-pot, orthogonal end-group modification and synthesis of $\alpha$-aldehyde, $\omega$-thiol-PVP.

\section{Model conjugation reactions and stimuli responsive release}

The overall goal of this research program is to synthesize polymer drug conjugates (using hydrophobic drugs) with the ability to undergo self-assembly into micellar-type structures, decorated with targeting ligands on the outside, for cell specific recognition and uptake, where the drug will then be released in response to a specific stimulus, i.e. $\mathrm{pH}$. With this in mind we tested the coupling efficiency of the end-groups with model small molecule compounds to mimic conjugate formation. We used glycine-DL-serine (Gly-DL-Ser) as a model compound to mimic the targeting ligand and conjugated it to the polymer's $\alpha$-chain end, by reductive amination (Scheme 4). Analysis by ${ }^{1} \mathrm{H}$ NMR spectroscopy showed the disappearance of the aldehyde signal (Fig. 7), presumably due to the formation of the PVP-peptide conjugate (9) via reductive amination.

The reactivity of the $\omega$-thiol was tested by performing a thiol-Michael addition click reaction between the PVP-peptide conjugate (9) with a phenyl acrylate, in order to link PVP with the phenyl moiety via a $\beta$-thio propionate. This linkage is particularly interesting because it is cleavable under mildly acidic conditions such as those found in endosomes ( $\mathrm{pH}$ 5.5), but it is stable at blood $\mathrm{pH}$ (7.4), allowing for selective release of the drug after endocytotic uptake. ${ }^{39}$ The reaction was carried out in a 50\% aqueous DMF solution, with respective ratios of [PVP-SH]:[phenyl acrylate]:[triethylamine (catalyst)] of $1: 1.5: 9 .^{40}$ The PVP-SH was formed in situ by reduction with sodium borohydride. ${ }^{24}{ }^{1} \mathrm{H}$ NMR spectroscopy analysis, of the purified product (11), revealed the appearance of aromatic protons assignable to phenyl ring, indicating a successful thiol-Michael addition click reaction (Fig. 7).

Finally, we evaluated the acid lability of the $\beta$-thio propionate by placing the polymer conjugate (11) in an aqueous solution buffered at $\mathrm{pH}$ 5.5. We followed the progress of the reaction by withdrawing samples, at intervals for TLC analysis. The release kinetics of phenyl moiety were then profiled by performing colour intensity measurements of the TLC plates, using the digitizing software UN-SCAN-IT (Silk Scientific Inc), in order to obtain a (reasonably) quantitative interpretation of the TLC analysis over time. A similar experiment was performed on a conjugate kept in phosphate buffer (pH 7.4) as a control. As shown in Fig. 8, the acid catalysed cleavage of the $\beta$-thio propionate ester linker, releasing the phenyl moiety, was $\sim 90 \%$ complete in just over $5 \mathrm{~h}$. Although the accuracy of the TLC study is not considered to be great, the release of the phenolate ion had a similar profile to that reported by Oishi et al. as determined via SEC. ${ }^{39}$ Consequently, this experiment confirmed the acid lability of the $\beta$-thio propionate ester linker. 


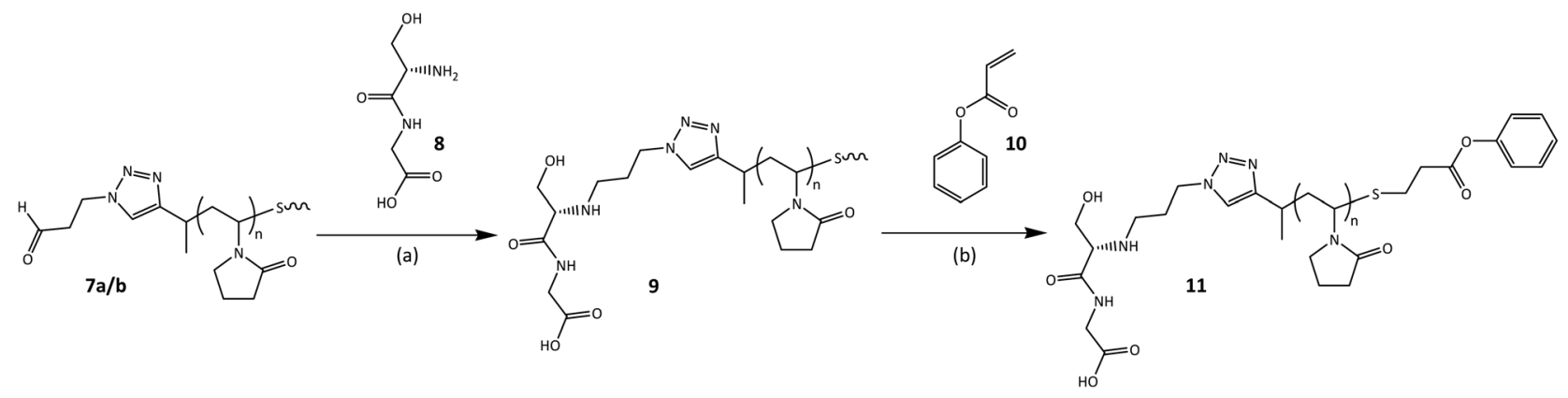

Scheme 4 Model conjugation reactions of $\alpha$-aldehyde, $\omega$-thiol functional PVP; with a model peptide (Gly-DL-Ser) and phenyl acrylate, utilising reductive amination and Michael addition chemistry, respectively; (a) sodium borate buffer ( $\mathrm{pH}=9.1$ ), $\mathrm{NaBH}_{3} \mathrm{CN}$, r.t.; and (b) $\mathrm{NaBH}_{4}$, triethylamine, r.t.

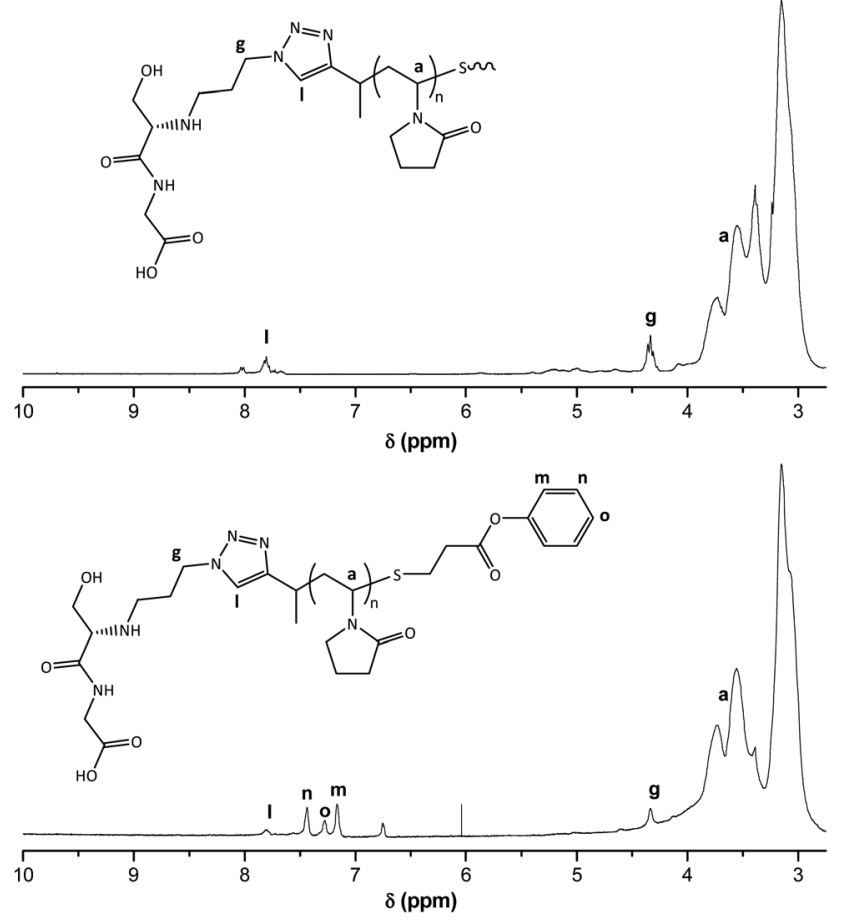

Fig. $7{ }^{1} \mathrm{H}$ NMR spectra of $\alpha$-dipeptide-PVP conjugate (top), and the $\alpha$-peptide, $\omega$-phenolate-PVP conjugate (bottom), both in DMSO- $d_{6}$.

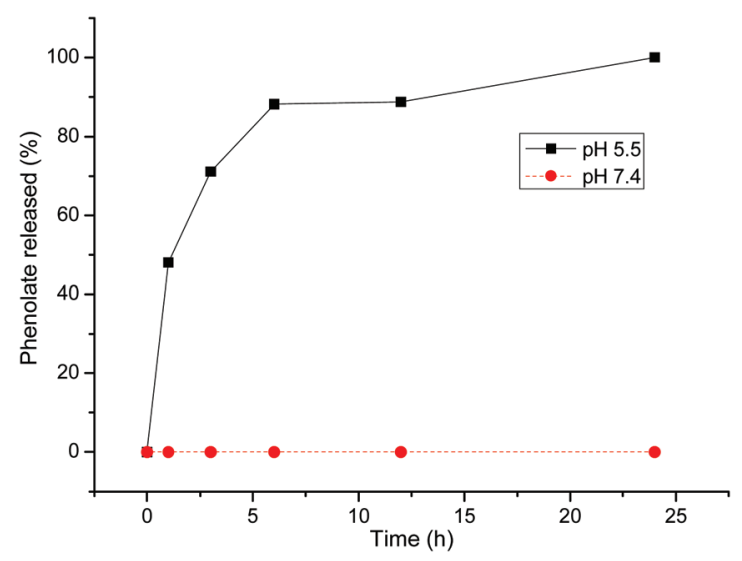

Fig. 8 Phenol release profile.

\section{Conclusions}

In conclusion, we have introduced a facile one-pot, orthogonal strategy for converting an $\alpha$-acetal, $\omega$-xanthate PVP into $\alpha$-aldehyde, $\omega$-thiol heterotelechelic PVP, by first aminolysing the $\omega$-xanthate chain end, using a primary amine, and then immediately lowering the $\mathrm{pH}$, to simultaneously capture excess primary amine and deprotect the acetal into an aldehyde, to afford the desired $\alpha$-aldehyde, $\omega$-thiol heterotelechelic PVP. The PVP was synthesized using a triazole-based xanthate RAFT agent. It was found that the triazole-ring alone as a substituent on the $\alpha$-carbon of the R-group, was not enough to stabilise the radical during polymerisation of NVP, yielding a poorly defined PVP. Good control over molar mass and $D$ was obtained after the leaving group was converted into a secondary radical. We also found that a cyclic acetal in close proximity to the nitrogen-containing triazole functionality was impossible to deprotect by acid catalysis, presumably due to unwanted protonation of the $\mathrm{N} 3$ atom of the triazole ring. This could be overcome by increasing the chain length between the acetal moiety and the triazole-ring (nitrogen source) and by making use of a linear acetal functionality. Finally we demonstrated the utility of the functional groups by conjugation with model small molecules. The $\alpha$-aldehyde end-group was used to couple glycine-DL-serine, via reductive amination, whilst the $\omega$-thiol end-group was utilised in a thiol-Michael addition click reaction to conjugate phenyl acrylate via an acid labile $\beta$-thio propionate ester linker. We also confirmed the acid lability of that linker. This development, of a modular, one pot protocol for functionalising polymer chain ends is very important for enhancing the versatility of biocompatible vinyl polymers for biomedical applications. Further efforts are currently directed at using the $\alpha$-aldehyde, $\omega$-thiol heterotelechelic PVP to prepare viable drug delivery systems.

\section{Acknowledgements}

This work is based on the research supported by the South African Research Chairs Initiative of the Department of Science and Technology (DST) and National Research Foundation (NRF) of South Africa (Grant No. 46855). 


\section{Notes and references}

1 G. N. Grover and H. D. Maynard, Curr. Opin. Chem. Biol., 2010, 14, 818.

2 I. Cobo, M. Li, B. S. Sumerlin and S. Perrier, Nat. Mater., 2015, 14, 143.

3 J.-F. Lutz and H. G. Börner, Prog. Polym. Sci., 2008, 33, 1.

4 M. A. Gauthier and H.-A. Klok, Chem. Commun., 2008, 2591.

5 P. J. Roth, F. D. Jochum, R. Zentel and P. Theato, Biomacromolecules, 2010, 11, 238.

6 K. L. Heredia, G. N. Grover, L. Tao and H. D. Maynard, Macromolecules, 2009, 42, 2360.

7 K. L. Heredia, L. Tao, G. N. Grover and H. D. Maynard, Polym. Chem., 2010, 1, 168.

8 M. Li, P. De, S. R. Gondi and B. S. Sumerlin, J. Polym. Sci., Part A: Polym. Chem., 2008, 46, 5093.

9 M. Li, P. De, S. R. Gondi and B. S. Sumerlin, Macromol. Rapid Commun., 2008, 29, 1172.

10 K. L. Heredia, Z. P. Tolstyka and H. D. Maynard, Macromolecules, 2007, 40, 4772.

11 C. Boyer, V. Bulmus, T. P. Davis, V. Ladmiral, J. Liu and S. Perrier, Chem. Rev., 2009, 109, 5402.

12 D. J. Siegwart, J. K. Oh and K. Matyjaszewski, Prog. Polym. Sci., 2012, 37, 18.

13 B. D. Fairbanks, P. A. Gunatillake and L. Meagher, Adv. Drug Delivery Rev., 2015, 91, 141.

14 G. Moad, E. Rizzardo and S. H. Thang, Aust. J. Chem., 2009, 62, 1402 .

15 M. Bathfield, F. D'Agosto, R. Spitz, M.-T. Charreyre and T. Delair, J. Am. Chem. Soc., 2006, 128, 2546.

16 K. T. Wiss, O. D. Krishna, P. J. Roth, K. L. Kiick and P. Theato, Macromolecules, 2009, 42, 3860.

17 K. L. Heredia, T. H. Nguyen, C.-W. Chang, V. Bulmus, T. P. Davis and H. D. Maynard, Chem. Commun., 2008, 3245.

18 S. R. Gondi, A. P. Vogt and B. S. Sumerlin, Macromolecules, 2007, 40, 474.

19 H. Willcock and R. K. O’Reilly, Polym. Chem., 2010, 1, 149.

20 P. J. Roth, C. Boyer, A. B. Lowe and T. P. Davis, Macromol. Rapid Commun., 2011, 32, 1123.
21 M. H. Stenzel, ACS Macro Lett., 2013, 2, 14.

22 C. Boyer, J. Liu, V. Bulmus, T. P. Davis, C. Barner-Kowollik and M. H. Stenzel, Macromolecules, 2008, 41, 5641.

23 P. J. Roth, M. Haase, T. Basché, P. Theato and R. Zentel, Macromolecules, 2010, 43, 895.

24 O. Shimoni, A. Postma, Y. Yan, A. M. Scott, J. K. Heath, E. C. Nice, A. N. Zelikin and F. Caruso, ACS Nano, 2012, 6, 1463.

25 G. Pound, J. M. McKenzie, R. F. M. Lange and B. Klumperman, Chem. Commun., 2008, 3193.

26 D. C. Wan, K. Satoh, M. Kamigaito and Y. Okamoto, Macromolecules, 2005, 38, 10397.

27 B. Nair, Int. J. Toxicol., 1998, 17, 95.

28 F. Haaf, A. Sanner and F. Straub, Polym. J., 1985, 17, 143.

29 A. N. Zelikin, G. K. Such, A. Postma and F. Caruso, Biomacromolecules, 2007, 8, 2950.

30 N. Akeroyd, R. Pfukwa and B. Klumperman, Macromolecules, 2009, 42, 3014.

31 T. W. Greene and P. G. M. Wuts, Protective Groups in Organic Synthesis, John Wiley \& Sons, New York, 3rd edn, 1999.

32 D. S. Dodd, A. C. Oehlschlager, N. H. Georgopapadakou, A. M. Polak and P. G. Hartman, J. Org. Chem., 1992, 57, 7226.

33 J. Sun, Y. Dong, L. Cao, X. Wang, S. Wang and Y. Hu, J. Org. Chem., 2004, 69, 8932.

34 A. Ilchev, R. Pfukwa, L. Hlalele, M. Smit and B. Klumperman, Polym. Chem., 2015, 6, 7945.

35 G. Pound, F. Aguesse, J. B. McLeary, R. F. M. Lange and B. Klumperman, Macromolecules, 2007, 40, 8861.

36 P. J. Kocienski, Protecting groups, Thieme Stuttgart, 3rd edn, 2005.

37 B. Schulze and U. S. Schubert, Chem. Soc. Rev., 2014, 43, 2522.

38 T. H. Fife and L. K. Jao, J. Org. Chem., 1965, 30, 1492.

39 M. Oishi, S. Sasaki, Y. Nagasaki and K. Kataoka, Biomacromolecules, 2003, 4, 1426.

40 G.-Z. Li, R. K. Randev, A. H. Soeriyadi, G. Rees, C. Boyer, Z. Tong, T. P. Davis, C. R. Becer and D. M. Haddleton, Polym. Chem., 2010, 1, 1196. 